\title{
O FLUXO E O REFLUXO DAS CULTURAS NAS DUAS MARGENS DO ATLÂNTICO
}

\author{
The cultures on both sides of the Atlantic
}

FabrícioVinhas Manini Angelo*

Resenha do Livro: HALL, Gwendolyn Midlo. Slavery and African Ethnicities in the Americas: Restoring the links. Chapel Hill, The University of North Carolina Press, 2005.

O livro Slavery and African Ethnicities in the América: Restoringthe links, sem tradução até o momento,deve ser considerado fundamental para quem deseja estudar a escravidão africana nas Américas bem como os diversos grupos étnicos africanos que vieram para o Novo Mundo e os que permaneceram na África, no contexto da escravidão moderna. Apesar de ser uma obra de síntese e que, por isso, não chega a dar elementos mais concretos sobre como restabelecer as conexões entre as etnias, ela aponta um caminho metodológico e levanta hipóteses que podem render bons frutos em pesquisas mais verticalizadas. Para GwendolynMidlo Hall, o cruzamento de fontes seriais/quantitativas sobre o tráfico atlântico de escravos com alguns documentos mais específicos - observados os devidos cuidados metodológicos - pode possibilitar um avanço significativo na compreensão acerca da escravidão nas Américas, da História da África e das diversas conexões estabelecidas entre estes temas no debate historiográfico.

* Mestre em História pela UFMG - Doutorando em Educação de UFMG - Telefones: (31) 3441-9539 ou (31) 8613-9787 - Rua.:Nilza Brito, n. 50, ap101 bl 8, BairroVitória, Belo Horizonte/ MG. - CEP: 31970-752 -Email: fabríciovinhas@gmail.com 
Para apresentar sua tese, a autora divide seu livro em duas partes: na primeira traça seus principais argumentos; e, na segunda, aponta algumas conexões entre as quatro principais regiões fornecedoras de escravos para as Américas. Então, para essa resenha, busca-se apresentar resumidamente os principais argumentos da autora para posteriormente estabelecer um balanço mais geral sobre o livro e sobre as implicações dele para a produção historiográfica contemporânea sobre essas temáticas.

Na primeira parte, Hall incialmente apresenta um resumo da história da escravidão na África, argumentando mais que o racismo foi fruto da escravidão do que a escravidão gerou o racismo. Mas para isso, a autora busca matizar a escravidão, buscando suas diferenças ao longo dos tempos e dos espaços nos quais existiu. Hall aponta que apesar da escravidão existir antes do período moderno, ela era bastante diferente em cada um dos locais nos quais se fez presente. Sua intenção ao se referir a estas diferenças, é rebater o argumento de pesquisadores que defendem que a escravidão foi apenas uma instituição importada da África junto com os seus povos, ou seja, para a historiadora, os europeus não só se aproveitaram desta instituição como a incentivaram e a mudaram completamente. Nesse sentido, os europeus têm a principal responsabilidade sobre a exploração dos povos africanos na América, pois transformaram a escravidão em um grande comércio que se utilizava de produtos extremamente destruidores (armas, tabaco e bebidas) para tornar os africanos extremamente dependentes dessas trocas. Além disso, a autora aponta a necessidade de estudar a escravidão, buscando compreender a acumulação de riqueza não só na Inglaterra, mas também em outros países europeus e também americanos, talvez retomando a tese de Eric Williams ${ }^{1}$.

Em seguida, a autora problematiza duas visões sobre os africanos nas Américas e na África, surgidas no século XX. A pri-

1 WILLIAMS, Eric. Capitalismo e escravidão. Rio de Janeiro, Americana, 1975. 
meira busca um passado mitológico de uma origem pan-africana nas Américas, ideia que segundo Hall realmente não existiu. A segunda visão é baseada em uma escola acadêmica muito respeitada (a antropologia cultural, que tem entre os seus representantes pesquisadores do calibre de Franz Boas, Fernando Ortiz, os irmãos Frances e Melville Herskovits e, posteriormente, Roger Bastide), mas que, para a autora, carrega uma problema metodológico, pois parte de um pressuposto teórico de acordo com o qual as culturas são imutáveis e, talvez por isso, insistem em conectar práticas contemporâneas africanas com as práticas vividas pelos afro-americanos hoje em dia, sem compreender que elas mudaram muito no trânsito entre as duas margens do Atlântico A partir da problematização destas duas visões, a autora estabelece uma metodologia para tornar visíveis as etnias dos africanos que chegaram às Américas. Tal metodologia passa pelo cruzamento dos dados fornecidos pelo tráfico atlântico, mas que tem que ir além, buscando compreender a redistribuição desses escravos recém-chegados. Dessa forma, com a melhora desses dados, a proposta metodológica da autora não está em buscar mais informações sobre os escravos na África, mas sim nas Américas, através de documentos numerosos que apontam a auto-identificação dos africanos. Assim, será possível compreender como esses grupos eram reunidos a partir da similitude de suas línguas/costumes, para facilitar o seu controle por parte dos senhores.

Ao final da primeira parte, Hall apresenta argumentos para corroborar a tese central do livro: a necessidade que os proprietários na América tinham de adquirir escravos, tanto quanto possível, de um mesmo grupo étnico ou falante de línguas mutuamente inteligíveis. Segundo a autora apesar dos recém chegados serem deliberadamente fragmentados em alguns lugares, a tendência era agrupá-los pelos seguintes motivos: 1) viagens mais rápidas e lucratividade com menos morte dos escravos; 2) integração gradual de outras partes da costa africana e concentração do comércio de escravos em algumas partes, assim primeiro existia o comércio de escravos ladinos oriundos da 
Senegâmbia, depois África Central Ocidental entra no comércio e, por fim, a Guiné ou África Ocidental e a quase insignificância de outras partes da África; 3) padrões de ventos, estações e distâncias para as viagens facilitando o contato de certas áreas africanas com certas áreas na América; 4) redes tradicionais de comércio preferência por etnias/grupos com maior aptidão em alguns ofícios/perícias ou mitos sobre a facilidade de determinados escravos africanos para algumas tarefas, por isso os minas como mineiros, os angolas como agricultores, os madagascar como plantadores de arroz; 5) preferência por recém chegados da África e que não foram utilizados em outros locais.

$\mathrm{Na}$ segunda parte, a autora utilizará suas considerações teórico-metodológicas para verticalizar o estudo sobre quatro partes da África que mais forneceram escravos para a América. Sendo assim, Hall inicia a análise buscando quebrar a tese, já tradicional, de que os escravos vindos da grande Senegâmbia tiveram pouco impacto sobre a escravidão americana. Para isso, ela argumenta que estes escravos foram os primeiros a manter contato com os europeus e por isso foram os primeiros a serem levados para a Europa, especialmente Península Ibérica. Lá aprenderam os idiomas locais, converteram-se ao cristianismo e depois foram reexportados para a América como escravos Ladinos, em uma referência aos escravos que já sabiam as línguas e a religião de seus proprietários. Desse modo, Hall afirma que tais cativos foram os primeiros a chegarem às terras americanas. Porém, por não serem suficientes para substituir os nativos quando eles não se adaptavam ao trabalho e por auxiliarem os indígenas (Arauak) em suas revoltas foram sendo deixados de lado. No entanto, existem indícios de que por causa das facilidades de navegação (regime de ventos) da Senegâmbia para algumas partes da América (Estado do Grão-Pará e Caribe) houve uma presença significativa desses escravos no Novo Mundo. Some-se que no baixo Peru, através de Cartagena de Índias, a importação de escravos para aquela região foi incentivada, pois se cobrava apenas um quarto do seu valor em impostos, enquanto 
para as outras etnias a taxa era de um terço, fato que indicaria uma preferência por tal grupo. No entanto, esses escravos mais uma vez foram deixados de lado por conta de seu espírito de revolta, já que sua região de origem era profundamente islamizada.

Em seguida, a autora analisa a baixa Guiné, enfatizando, inicialmente, a ambiguidade que sempre esteve presente nesta nomenclatura, utilizada para identificar uma região que, no limite, iria do Rio Senegal até o Rio Orange. Além, é claro, das inúmeras subdivisões que compõem essa enorme costa. Por causa disso, seria muito difícil ligar uma etnia em especifico com um agrupamento desses escravos na América. No entanto, é possível agrupá-los em solo americano devido à língua geral da Mina, criada a partir de um universo de mesclas culturais e também através da já documentada e estudada presença da língua Mina-Jeje. Conclusão semelhante a de Mariza de Carvalho Soares em sua tese ${ }^{2}$. Segundo Hall, esse grupo foi muito influente na América devido à sua tradição de fugas, quilombos, revoltas e conspirações e, também, pelo mito da maior disposição para trabalhar com ouro e outros metais.

Mais adiante, a autora discute a influência dos escravos embarcados na região da Baía de Biafra. Para Hall, apesar da região ser considerada, para todos efeitos, uma parte da baixa Guiné, ou seja, terras que estão a leste do delta do Niger e ao norte dos Camarões, alguns dos escravos ali embarcados têm características culturais muitos específicas, o que justificaria sua análise em separado. Apesar desse tráfico nunca ter sido majoritário, a característica de apresentar uma razão de sexo mais equilibrada, quando não favorecendo as mulheres, indicaria algumas pistas a seguir. Entre as etnias embarcadas nestes portos, os Igbos sempre tiveram maior proporção de mulheres em comparação às outras etnias envolvidas no tráfico. Apesar das

2 SOARES, Mariza Carvalho. Devotos da cor: identidade étnica, religiosidade e escravidão no Rio de Janeiro do século XVIII. Rio de Janeiro: Civilização Brasileira, 2000. 
polêmicas sobre a existência desse grupo enquanto unidade cultural, muitos deles se auto-identificaram em processos localizados por Hall na Louisiana. Mas a justificativa para a maior presença de mulheres Igbo é justamente a menor tendência desse grupo se fechar, ou seja, as Igbo tinham maior tendência a se relacionarem e a terem filhos com indivíduos de outras etnias.

Ao final na segunda parte, Hall analisa os escravos que embarcaram na costa da África central ocidental e em Moçambique, pois este grande grupo foi de longe o mais exportado para as Américas, representando algo entre $40 \%$ e $45 \%$ das peças. Isso porque, para autora, aquela foi a região que mais recebeu influência dos europeus e onde até criaram o comércio de escravos. Tais fatos, em partes, são explicados por causa da existência do Reino do Congo, já muito cedo cristianizado, e pelo estabelecimento de europeus, de "lançados" e de oriundos de São Tomé no interior do continente africano. Não se deve diminuir a importância da diplomacia, uma vez que o Rei do Congo era aliado de Portugal, das disputas entre potências europeias para controle da região - como os embates entre holandeses e portugueses, ao longo do século XVII - e, por último, da forte presença brasílica após a retomada de Luanda, em 1648. Tudo sempre regado pelo comércio mais destrutivo, ao qual a autora já havia se referido, marcado pelo uso de armas nas trocas, principalmente com os holandeses e depois com os ingleses, pelo tabaco e pela aguardente do Brasil. Devido à influência europeia na região, de boas rotas de navegação e com isso barateamento dos custos do escravo, uma facilidade na compreensão das línguas, que apesar de serem diferentes eram relativamente fáceis de serem aprendidas pelos diversos grupos, proximidades de sua religião/cosmovisão possibilitou um agrupamento desses indivíduos em diversas partes das Américas.

De modo geral, o que GwendolynMidlo Hall pretendia com esse livro era construir um método para entender processos de formação das culturas na América, levando em consideraçãoos africanos. 
Indo, dessa forma, além de visões simplistas sobre as identidades dos ancestrais africanos. Além disso, para a historiadora seria importante observar a riqueza e a complexidade das migrações e da vida durante o período que analisou, mantendo o cuidado de evitar a transferência algumas conclusões de um período para os outros. Desviar-se de generalizações e manter sempre a idéia de mudança no horizonte é fundamental. Portanto, a crioulização ou a mestiçagem foram processos que envolveram toda a população das Américas, e muitas vezes com elementos específicos de algumas culturas africanas.

Ao finalizar este texto, deve-se fazer um convite a leitura do livro de GwendolynMidlo Hall, por ser um texto fundamental para quem pesquisa a escravidão e o tráfico negreiro, assim como a história e as culturas africanas e americanas. No entanto, este livro é apenas um ponto de partida para uma renovação metodológica que visa compreender a contribuição dos africanos para a formação do América. Isto porque, a proposta da autora vai além de compreensão genérica sobre a música, a arte, os valores estéticos, a cosmovisão ou a religiosidade que os africanos trouxeram para as Américas. Hall afirma, brilhantemente, que é possível ir além, quando compreende-se que as culturas estão sempre em movimento. Portanto, seria possível nuançar a influência de alguns grupos africanos para alguns períodos e regiões das Américas. Isto é, a partir da compreensão das ondas africanas de determinada origem é plausível chegar a indícios muito específicos sobre os papéis exercidos por determinados grupos de escravos africanos na conformação cultural de diversos espaços e contextos americanos.

Recebido em 14 de abril de 2014

Aprovado em 29 de setembro de 2015 